\title{
Formation of Copper Nickel Bimetallic Nanoalloy Film Using Precursor Inks
}

\section{Chaitanya G. Mahajan1, Amanda Marottaㄹ, Bruce E. Kahn³ ${ }^{3}$ Mark Irving1, Surendra Gupta ${ }^{4}$, Richard Hailstone ${ }^{5}$, Scott A. Williams², Denis Cormier ${ }^{1,3^{*}}$}

\author{
${ }^{1}$ Department of Industrial and Systems Engineering, Rochester Institute of Technology, Rochester, NY, USA \\ ${ }^{2}$ School of Chemistry and Materials Science, Rochester Institute of Technology, Rochester, NY, USA \\ ${ }^{3}$ AMPrint Center, Rochester Institute of Technology, Rochester, NY, USA \\ ${ }^{4}$ Department of Mechanical Engineering, Rochester Institute of Technology, Rochester, NY, USA \\ ${ }^{5}$ Center for Imaging Science, Rochester Institute of Technology, Rochester, NY, USA \\ Email: cgm5952@rit.edu, arm7402@rit.edu, bekeie@rit.edu, meieie@rit.edu, skgeme@rit.edu, rkhpci@rit.edu, sawppr@rit.edu, \\ *drceie@rit.edu
}

How to cite this paper: Mahajan, C.G. Marotta, A., Kahn, B.E., Irving, M., Gupta, S., Hailstone, R., Williams, S.A. and Cormier, D. (2019) Formation of Copper Nickel Bimetallic Nanoalloy Film Using Precursor Inks. Materials Sciences and Applications, 10, 349-363. https://doi.org/10.4236/msa.2019.104026

Received: March 6, 2019

Accepted: April 21, 2019

Published: April 24, 2019

Copyright $\odot 2019$ by author(s) and Scientific Research Publishing Inc. This work is licensed under the Creative Commons Attribution International License (CC BY 4.0).

http://creativecommons.org/licenses/by/4.0/

(c) (i) Open Access

\begin{abstract}
Precursor (Metal-organic decomposition (MOD)) inks are used to fabricate $2 \mathrm{D}$ and $3 \mathrm{D}$ printed conductive structures directly onto a substrate. By formulating a nanoalloy structure containing multiple metals, the opportunity to modify chemical and physical properties exists. In this paper, a copper-nickel bimetallic nanoalloy film was fabricated by mixing copper and nickel precursor inks and sintering them in vacuum. The individual elemental inks were formulated and characterized using SEM, EDS, and XRD. During thermal processing, elemental copper forms first and is followed by the formation of bimetallic copper-nickel alloy. The encapsulation of the underlying copper by the nickel-rich alloy provides excellent oxidation resistance. No change in film resistance was observed after the film was exposed to an oxygen plasma. Nanoalloy films printed using reactive metallic inks have a variety of important applications involving local control of alloy composition. Examples include facile formation of layered nanostructures, and electrical conductivity with oxidative stability.
\end{abstract}

\section{Keywords}

Copper-Nickel, Functional Printing, Metal Organic Decomposition, Printed Nanoalloy, Precursor Ink

\section{Introduction}

Functional printing has evolved from fabricating parts using a single material, to 
make multifunctional components using two or more materials. There is tremendous interest in functional printing, where different printing techniques [1] are used to make devices such as antennas [2] [3] [4] [5], electrical circuit components [6] [7] [8] [9] [10], and sensors [11] [12] [13] [14]. Metallic inks are often used to fabricate $2 \mathrm{D}$ and $3 \mathrm{D}$ structures to conduct heat and electricity. $\mathrm{Nu}$ merous examples of printing of copper [15]-[20] and silver [21]-[26] inks on solid and flexible substrates have been demonstrated in the literature. These inks are either metal nanoparticle or precursor (metal-organic decomposition (MOD) inks. The opportunity to tune the physical and chemical properties of a material could be achieved by mixing several metal inks together to create an alloy. A nanoalloy is a solid state solution containing atoms or molecules of two or more metals [27]. Elements which are immiscible in the bulk form or have a large miscibility gap can be mixed at the nanoscale to produce properties that differ from those of the individual bulk materials [28] [29]. The physical and chemical properties of nanoalloys can be enhanced by varying their structure, composition and particle size to provide properties having applications in biomedical devices, electronics, engineering, and catalysis [30] [31] [32] [33]. It is generally easier to control the structure of nanoalloys using bottom-up synthesis where single atoms or molecules are assembled to form a nanostructure [34]. When using precursor inks, different structures are possible depending on the decomposition profiles, solid loading, and reactivity of individual inks. If the decomposition profiles are identical, then a well-mixed structure is possible. If the decomposition profiles are different, it is possible to synthesize a variety of different structures, for example core-shell structures [35] [36] [37].

In recent years, copper nickel nanoalloys have gained considerable interest in the research community due to the conductivity of copper and the corrosion resistance of nickel. For this reason, they are potential candidates as electrodes in corrosive environments. CuNi alloys are used in marine applications [38], solid oxide fuel cells [39], glucose sensors [40], hydrogenation of refined soybean oil [32], photodegradation of organic dyes [41], and in hyperthermia therapy [42]. Different methods have been used to fabricate $\mathrm{CuNi}$ nanoalloy particles. Chemical methods include electrochemistry [40], hydrothermal reduction [41] [43], microemulsions [44] [45], mechanical alloying [30] [46], reduction of polyols [30] [47] or salts [48] [49], and solution combustion [50] [51]. Synthesizing such nanoalloy particles is often accompanied by undesirable contamination in the final composition. For example, impurities from the metal salts may not be completely removed by repeated washing and drying of the nanoparticles. Oxidation is also a problem, requiring special care during washing, filtering and drying of the nanoalloy particles. Printing a precursor nanoalloy ink and directly sintering in situ on the substrate will eliminate some of the problems encountered in the synthesis and use of premade nanoparticles.

The printing of functional devices using nanoalloys is still at a relatively early stage and has not been widely explored. Inks containing nanoalloy particles can be printed using a wide variety of printing techniques to create customized parts 
for many specific applications. In this work, a nanoalloy precursor ink containing copper and nickel is prepared which can be reduced to a binary alloy of the desired composition. Different characterization techniques such as EDS, TEM, and XRD were used to confirm the formation of nanoalloys. The change in resistivity of the sintered conductive film on exposure to oxygen plasma is reported.

\section{Experimental Section}

\subsection{Materials}

All chemicals used were analytical grade. Nickel formate dihydrate (molecular weight (MW): 184.77) and copper formate tetrahydrate (molecular weight (MW): 225.65) were purchased from Alfa Aesar, USA. Ethylene diamine was purchased from Fisher Scientific, USA and ethylene glycol was purchased from Sigma-Aldrich, USA. These chemicals were used without further purification. Glass microscope slides (Thermo Scientific, USA), Kapton ${ }^{\circledR}$ film (DuPont USA, 5 mil thick) and single crystal quartz (MTI corporation, USA) were used as substrates and were cleaned with isopropyl alcohol before ink deposition.

\subsection{Ink Formulation}

To formulate copper precursor (MOD) ink, ethylene glycol (EG) (2 ml) was used as the solvent. Ethylene diamine (ED) $(0.36 \mathrm{ml}, 5.39 \mathrm{mmol})$ was used as the ligand and was added to the ethylene glycol. The mixture was stirred at room temperature for 15 minutes. Copper formate tetrahydrate $(0.61 \mathrm{~g}, 2.70 \mathrm{mmol})$ was added to the solution and stirred at room temperature for one hour. A dark blue color was formed indicating the formation of a copper amine complex. The ink was filtered through a $0.2 \mu \mathrm{m}$ syringe filter. The nickel precursor (MOD) ink formulation was adapted from the patent published by Ginley et al. [52]. To formulate the nickel ink, ethylene glycol $(2 \mathrm{ml})$ was used as the solvent. Ethylene diamine $(0.36 \mathrm{ml}, 5.39 \mathrm{mmol})$ was used as the ligand and added to the ethylene glycol. The mixture was stirred at room temperature for 15 minutes. Nickel formate $(0.50 \mathrm{~g}, 2.70 \mathrm{mmol})$ was added to the solution and stirred at room temperature for one hour. The ink turned from green to purple indicating the formation of a nickel amine complex. The ink was filtered through a $0.2 \mu \mathrm{m}$ syringe filter. To formulate the alloy inks, copper and nickel inks were mixed in the desired ratio and stirred at room temperature. The same ligand molecule (ethylene diamine) and carrier solvent (ethylene glycol) were used to prepare the individual inks to avoid immiscibility and solubility issues during mixing.

\subsection{Characterization}

Thermogravimetric analysis (TGA) and differential thermal analysis (DTA) (Shimadzu DTG-60, Japan) were performed by heating samples in a platinum pan from room temperature to $300^{\circ} \mathrm{C}$ at $10^{\circ} \mathrm{C} / \mathrm{min}$. For thermal analysis mass spectrometry (TA-MS), $4.0 \mu \mathrm{l}$ of the ink was placed onto clean glass wool inside 
of a 0.25 inch OD glass tube. These were then placed into the autosampler tray (Gerstel TDSA, Germany) with the open ends blocked with Viton ${ }^{\circledR}$ O-rings. Each tube was individually loaded into the heated chamber at $30^{\circ} \mathrm{C}$, and helium flowed through the tube at $100 \mathrm{ml} / \mathrm{min}$. Effluent from the tube was split, with 1.0 $\mathrm{ml} / \mathrm{min}$ directed into the mass spectrometer (Agilent 5973, USA) through a heated one meter transfer line. The remainder of the effluent was vented. The sample tube was heated from room temperature to $280^{\circ} \mathrm{C}$ at a rate of $10^{\circ} \mathrm{C} / \mathrm{min}$. Surface morphology and elemental analysis of the printed films were analyzed using a scanning electron microscope having an energy-dispersive $\mathrm{x}$-ray spectroscopy (EDS) detector (Jeol JSM-IT100LA, USA). The drop cast films were characterized by a RIGAKU DMax-IIB x-ray diffractometer. Transmission electron microscopy (TEM) (Jeol 2010, USA) was used at $200 \mathrm{kV}$ to obtain the SAED pattern for the sintered alloy film. Infrared (IR) spectroscopy (Shimadzu IR Prestige-21 with ATR) was used to analyze the precursor (MOD) inks, ethylene glycol, and ethylene diamine.

To study the effect of oxygen exposure on resistance, the sintered film was exposed to an $\mathrm{O}_{2}$ plasma using a SurFxAtomflo ${ }^{\mathrm{TM}} 400$ atmospheric plasma system. This system generates plasma using a helium-oxygen gas mixture to create an oxidizing environment. The plasma head was mounted on a linear stage to move in $\mathrm{X}$ and $\mathrm{Y}$ direction. The $\mathrm{Z}$ height between the sample and the head was kept constant at $10 \mathrm{~mm}$. For each pass, the power of the plasma was set to 100 W. Helium and oxygen gas flow rates of $15.00 \mathrm{l} / \mathrm{min}$ and $0.30 \mathrm{l} / \mathrm{min}$ were used.

\subsection{Inkjet Printing}

The inks were printed onto a substrate using a Fuji Dimatix inkjet printer (DMP 3000). The printer uses a piezoelectric ink cartridge having a single row of 16 nozzles with a drop volume of $10 \mathrm{pl}$. The print head temperature and the voltage were adjusted for individual inks before printing. For electrical measurements, a solid square film $(1 \mathrm{~cm} \times 1 \mathrm{~cm})$ was printed on a glass substrate and sintered in a vacuum furnace.

\section{Results and Discussion}

\subsection{Copper and Nickel Ink Characterization}

The copper and nickel precursor (MOD) inks contain the metal formate salts complexed by ethylenediamine. Formate ions were used because of their low molecular weight and volatility [53]. Furthermore, the decomposition of formate is accompanied by the release of carbon dioxide and molecular hydrogen, (Equation (1) \& Equation (2)), the latter of which generates a reducing atmosphere, thus limiting the amount of oxidation of the reduced metals [36].

$$
\begin{gathered}
2 \mathrm{HCOO}^{-} \rightarrow 2 \mathrm{CO}_{2}+\mathrm{H}_{2}+2 \mathrm{e}^{-} \\
\mathrm{M}^{2+}+2 \mathrm{e}^{-} \rightarrow \mathrm{M}^{0}(\mathrm{M}=\mathrm{Cu} \text { or } \mathrm{Ni})
\end{gathered}
$$

The bidentate ethylenediamine was used in the formation of the metal com- 
plex to enhance the reduction efficiency, achieve complex stability, and increase solubility in the solvent. Ethylene glycol was used as a solvent to obtain suitable solubility and rheological properties for inkjet printing. The high boiling point $\left(\sim 198^{\circ} \mathrm{C}\right)$ of ethylene glycol also enables reduction of the complex to metal at elevated temperature.

Figure 1 shows the primary IR absorbance for ethylene glycol, ethylenediamine, and the copper and nickel precursor (MOD) inks. As expected, all of the EG peaks in the ink spectra match those associated with neat EG. EG vibrational transitions in the ink do not exhibit any evidence of metal-EG interactions through vibrational peak damping or significant spectral band shifting. The IR spectra (Figure 1) also confirms that the EDA is directly complexed to the metals as indicated by dampening of the IR frequencies assigned to amine transitions.

Figure 2(A) and Figure 2(B) show the TA-MS results for copper and nickel precursor inks respectively. For both the inks, the thermal decomposition occurs in two stages. The solvent evaporates first, followed by the metal reduction. In the first stage $\left(<130^{\circ} \mathrm{C}\right)$, ethylene glycol and water are released leaving behind the metal complex. The reduction of the copper and nickel precursor inks occur at $\sim 155^{\circ} \mathrm{C}$ and $\sim 220^{\circ} \mathrm{C}$ respectively. The metal complex decomposition evolves carbon dioxide, carbon monoxide and ethylenediamine, consistent with the reactions in Equation (1) and Equation (2). The final solid loadings of copper and nickel are $6.5 \%$ and $4.5 \% \mathrm{w} / \mathrm{w}$ respectively.

Figure 3 shows scanning electron microscopy (SEM) images of the reduced copper and nickel from the precursor inks. The metal deposits are composed of sintered nanoparticles having an average particle size around $500 \mathrm{~nm}$. The size of the particles are dependent on various factors such as the rates of reaction,

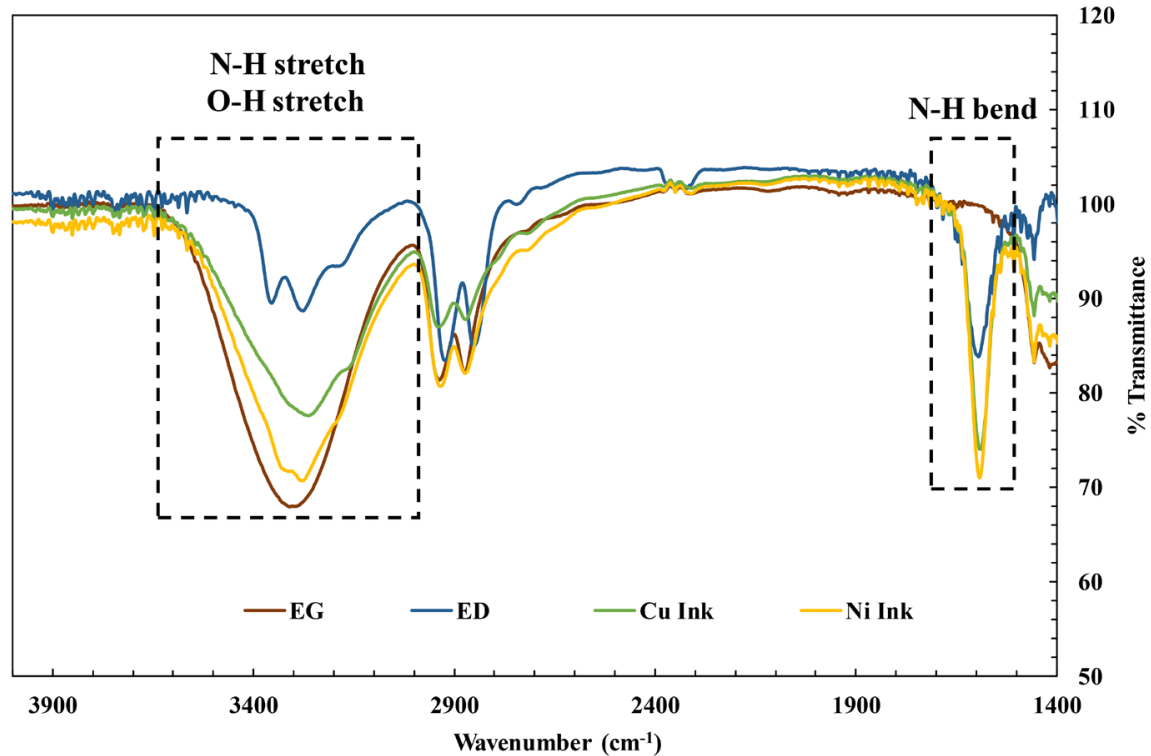

Figure 1. IR spectra of ethylene glycol (EG), ethylenediamine (ED), copper ink and nickel ink. 


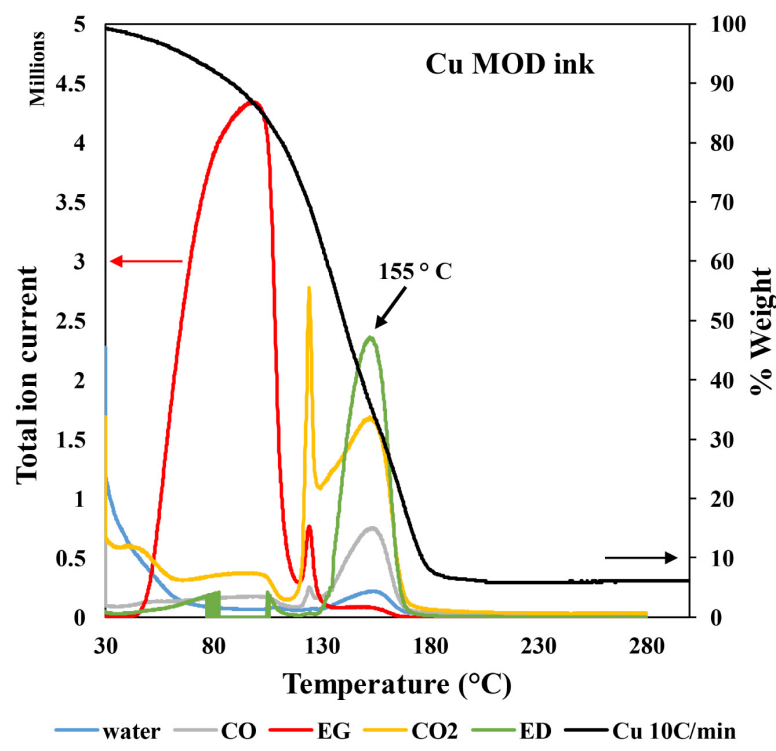

(A)

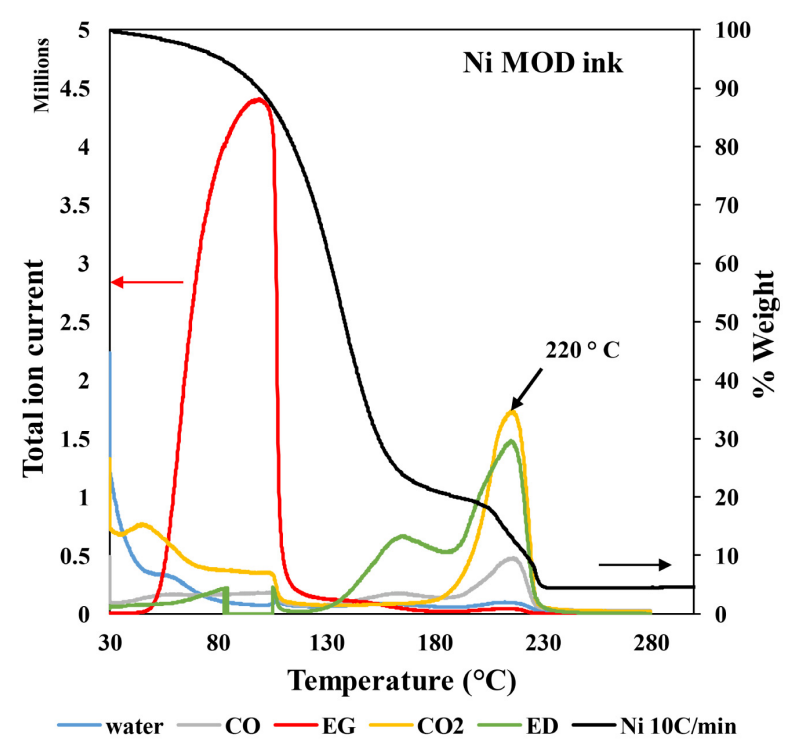

(B)

Figure 2. Thermal analysis mass spectrometry (TA-MS) of (A) Cu and (B) Ni precursor inks.

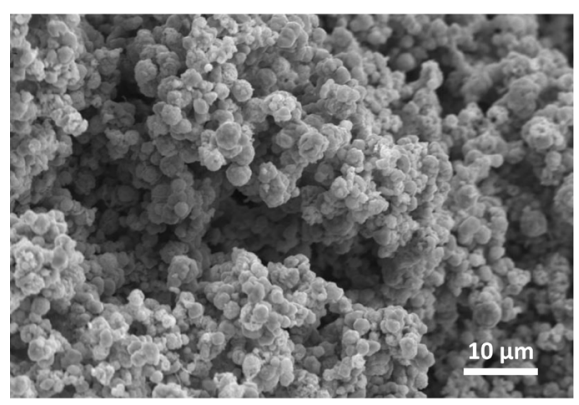

(A)

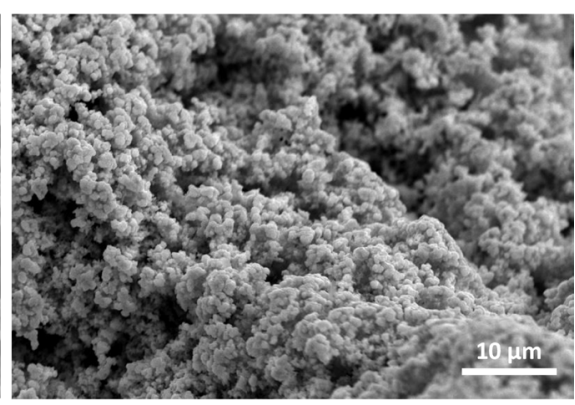

(B)

Figure 3. SEM image of (A) copper and (B) nickel film sintered in N2 atmosphere.

nucleation and crystal growth [54]. Small particles can coalesce into larger particles. XRD analysis confirmed the presence of elemental copper and nickel (Figure 4).

Kal peak positions were obtained from Pearson type VII peak decomposition [55]. Precise lattice parameter was determined from a plot of lattice parameter versus $\cos ^{2} \theta / \sin \theta$ [56]. The experimental lattice parameters for copper and nickel were found to be $3.6145 \AA$ and $3.5242 \AA$ respectively. These values are in good agreement with the lattice parameter for pure copper (3.614 $\AA$, PDF\# 00-004-0836) and pure nickel (3.524 $\AA$, PDF\# 00-004-0850).

Figure 5 shows the differential thermal analysis for copper and nickel inks heated up to $300^{\circ} \mathrm{C}$ at $10^{\circ} \mathrm{C} / \mathrm{min}$. The reduction of copper and nickel to their elemental states occurs in four stages. The first stage is same for both the inks and includes evaporation of ethylene glycol and water as indicated by the endothermic region below $140^{\circ} \mathrm{C}$. The second stage includes reduction of the metal complex as indicated by the exothermic range up to $155^{\circ} \mathrm{C}$ for copper and around $200^{\circ} \mathrm{C}$ for nickel. The exothermic ranges for the metals match the TA-MS 


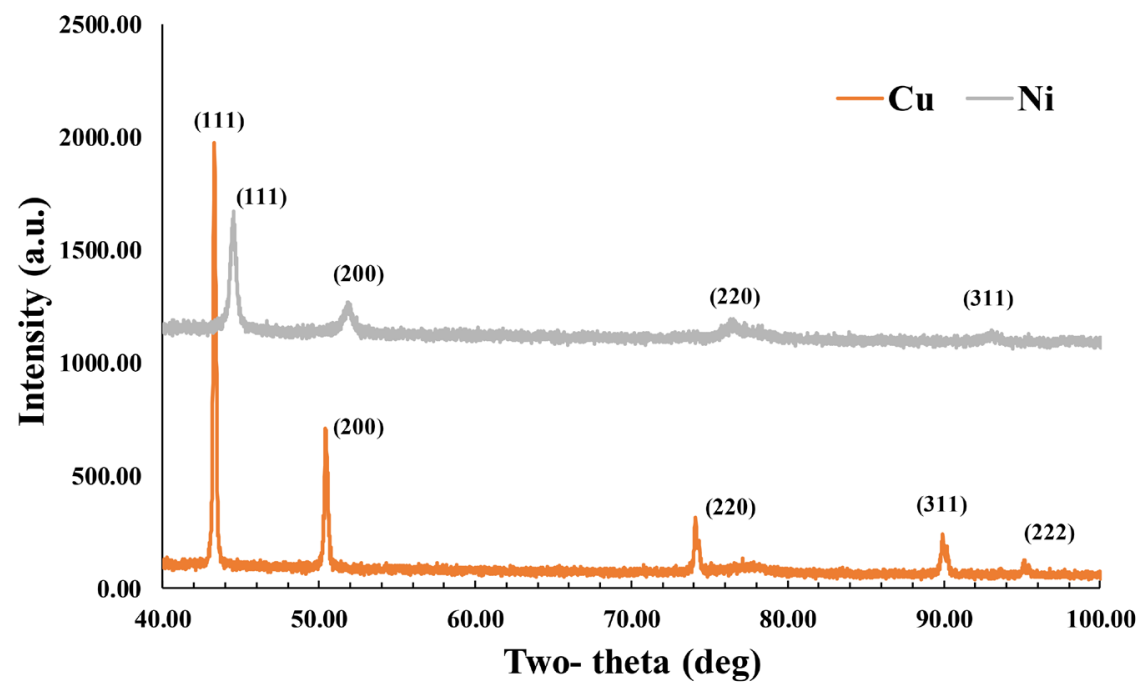

Figure 4. X-ray diffraction patterns for reduced copper and nickel films on quartz substrate.

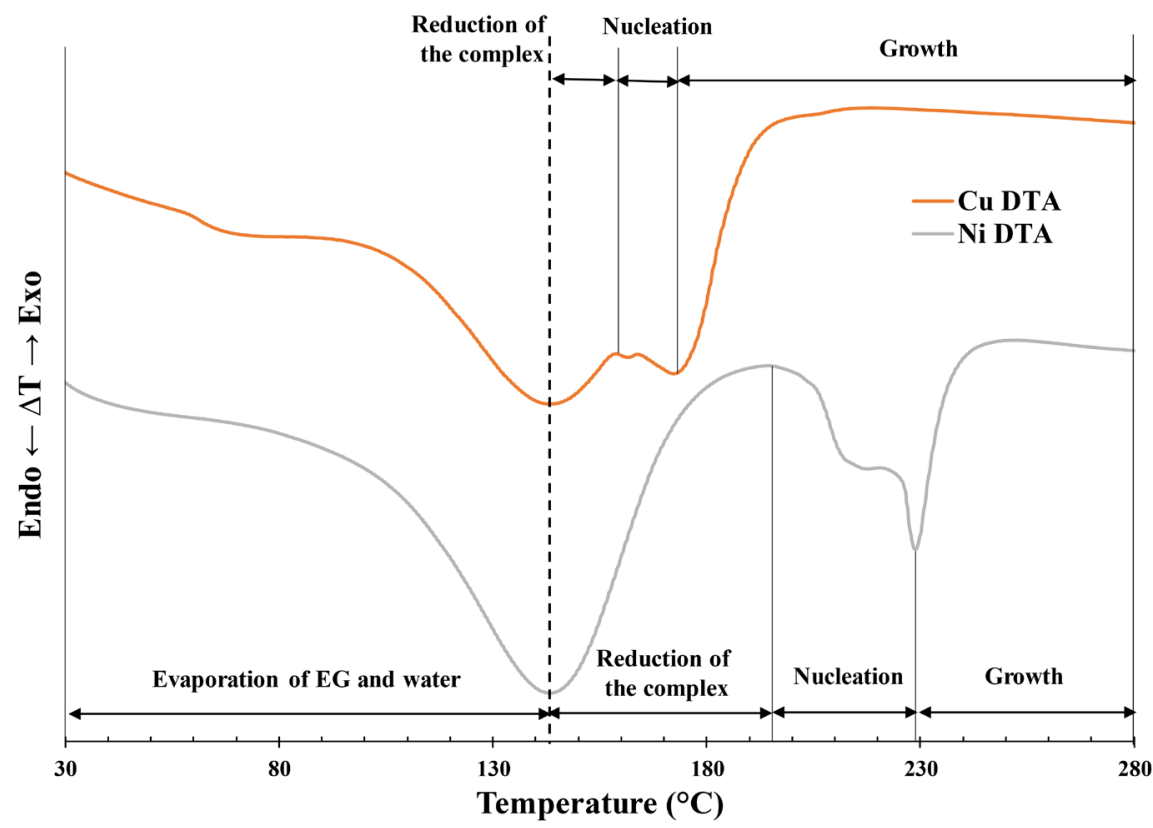

Figure 5. Differential thermal analysis for copper MOD ink and nickel MOD ink at $10^{\circ} \mathrm{C} / \mathrm{min}$

(Figure 2). Nucleation takes place in the third stage. This is indicated by endothermic range from $\sim 160^{\circ} \mathrm{C}-180^{\circ} \mathrm{C}$ for $\mathrm{Cu}$, and $\sim 195^{\circ} \mathrm{C}-230^{\circ} \mathrm{C}$ for Ni. Nucleation can be affected by impurities present in the ink and/or substrate. Impurities may inhibit or accelerate the rate of the reactions. The fourth stage is the crystal growth indicated by exothermic ranges $>\sim 180^{\circ} \mathrm{C}$ for $\mathrm{Cu}$ and $\sim 230^{\circ} \mathrm{C}$ for Ni.

\subsection{Alloy Characterization}

Figure 6 shows a proposed schematic overview of the nanoalloy formation process. The copper and nickel nuclei formed at the beginning of the reduction 


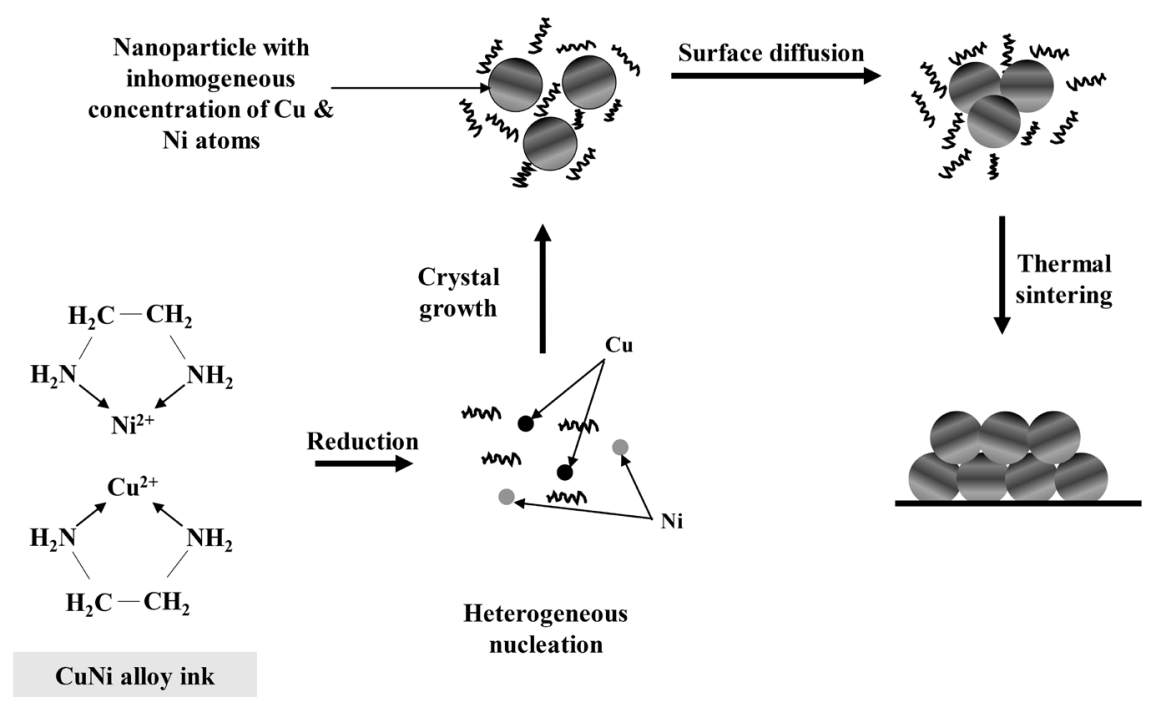

Figure 6. Schematic overview of formation of nanoalloy structure onto a substrate.

reaction result in copper-nickel nanoalloy particles. These nanoalloy particles subsequently sinter into a continuous film.

In order to observe the endothermic and exothermic events for the formation of bimetallic film, DTA was carried out for $\mathrm{Cu}, \mathrm{Ni}$ and $\mathrm{CuNi}$ MOD inks at $2^{\circ} \mathrm{C} / \mathrm{min}$ (Figure 7). As shown above for $10^{\circ} \mathrm{C} / \mathrm{min}$, the reduction of the metal complex to elemental metal was observed in four stages (S1 - S4). The first stage (S1, solvent evaporation) was the same for all inks. The copper complex reduces at a lower temperature than nickel due to its lower reduction potential. For the $\mathrm{CuNi}$ alloy ink, copper reduces first and provides nucleation sites for nickel which reduces later when the temperature is increased. The endothermic peak for the nickel reduction takes place at a lower temperature suggesting that the presence of copper nanoparticles may catalyze the reaction. DTA data suggests the presence of two phases which are copper and copper nickel alloy. The resulting alloy films have a layered structure with copper reducing first at the substrate and a non-uniform distribution of $\mathrm{Cu}$ and $\mathrm{Ni}$ atoms (CuNi) alloy on top of the reduced copper.

The EDS elemental mapping (Figure 8(A)) shows no segregation of copper and nickel (within the measurement resolution). The $\mathrm{x}$-ray diffraction pattern in Figure $8(C)$ shows peaks for both a copper phase and a copper-nickel alloy phase. This corroborates the results obtained from the DTA where copper reduced first and the copper-nickel alloy deposited on the reduced copper. The lattice parameter obtained for the copper peak was $3.6143 \AA$, and from the copper-nickel alloy peak was $3.5318 \AA$ respectively. Using Vegard's law, the composition of the alloy phase was estimated to be $\mathrm{Cu}_{8} \mathrm{Ni}_{92}$.

Figure 9(A) shows the TEM image of drop casted CuNi film sintered at $2^{\circ} \mathrm{C} / \mathrm{min}$ in a vacuum furnace. The film was removed from the substrate and placed on the TEM grid for analysis. The nanoparticles and grain boundaries are easily seen. Figure 9 (B) shows the electron diffraction pattern obtained from the 


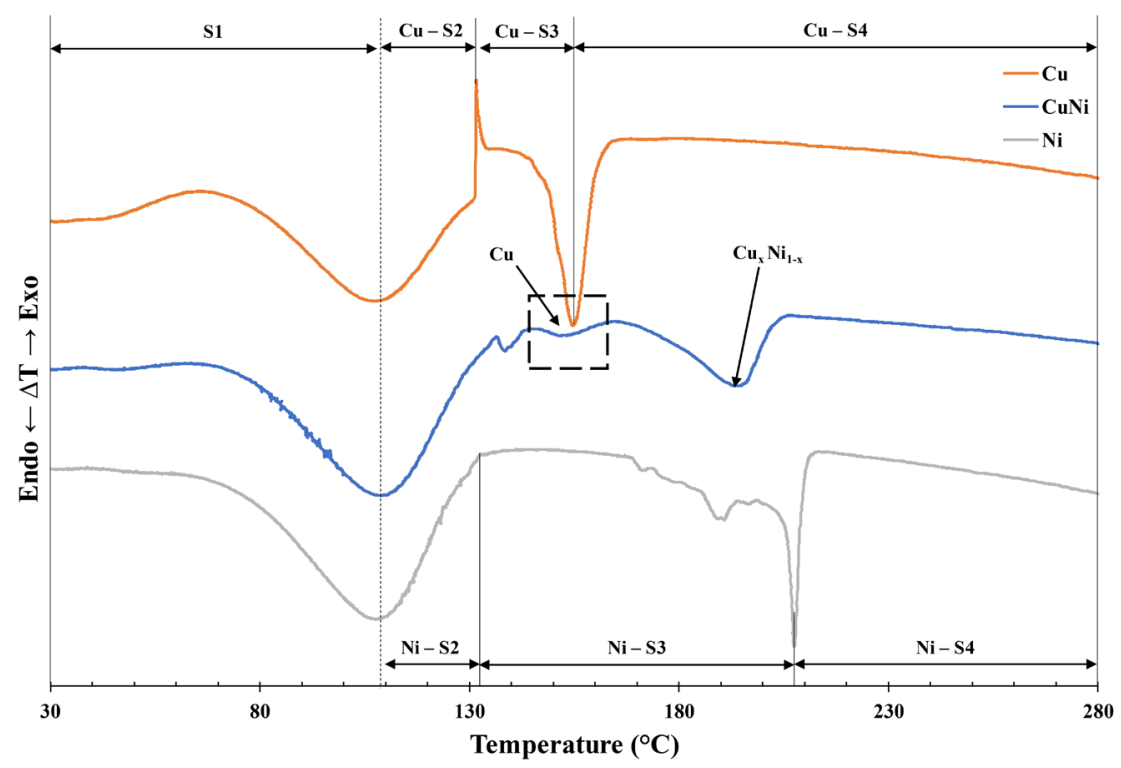

Figure 7. Differential thermal analysis for copper MOD ink, nickel MOD ink, and CuNi alloy MOD ink.

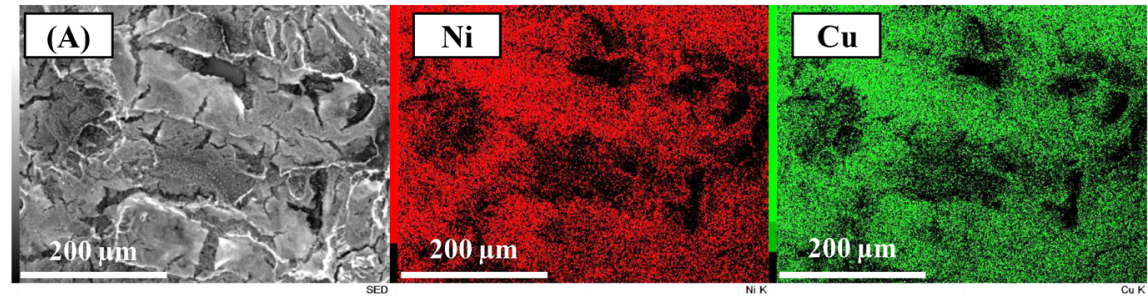

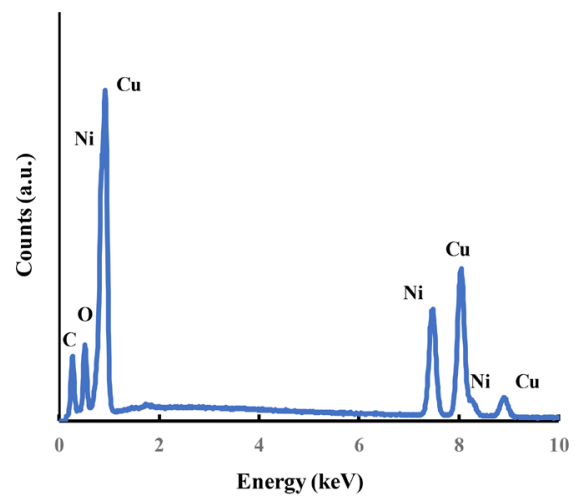

(B)

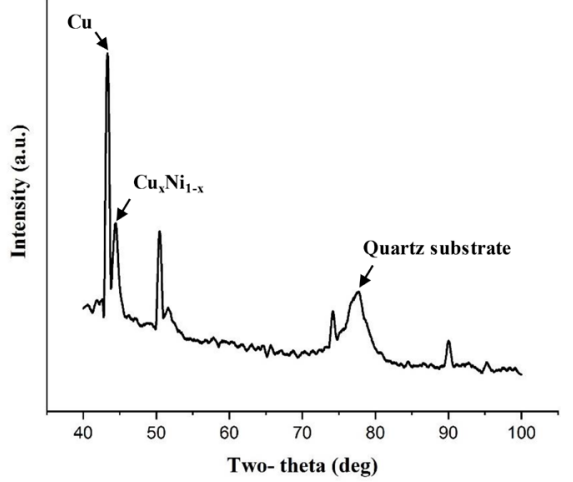

(C)

Figure 8. (A) EDS elemental maps on samples sintered in a vacuum furnace. (B) EDS spectrum of the sintered sample. (C) X-ray diffraction pattern for sintered film on quartz substrate.

same area shown in Figure 9(A). The $d$ spacing from electron diffraction data was used to calculate the lattice constant and then was averaged over all four lattice constants. The lattice constants obtained from the TEM analysis were not consistent with either a pure copper or pure nickel phase, indicating an alloy formation. Other unresolved ring patterns may be due to impurities, amorphous materials, or formation of small amounts of metal oxides $(\mathrm{NiO}, \mathrm{CuO}$ or $\mathrm{NiCuO})$. 


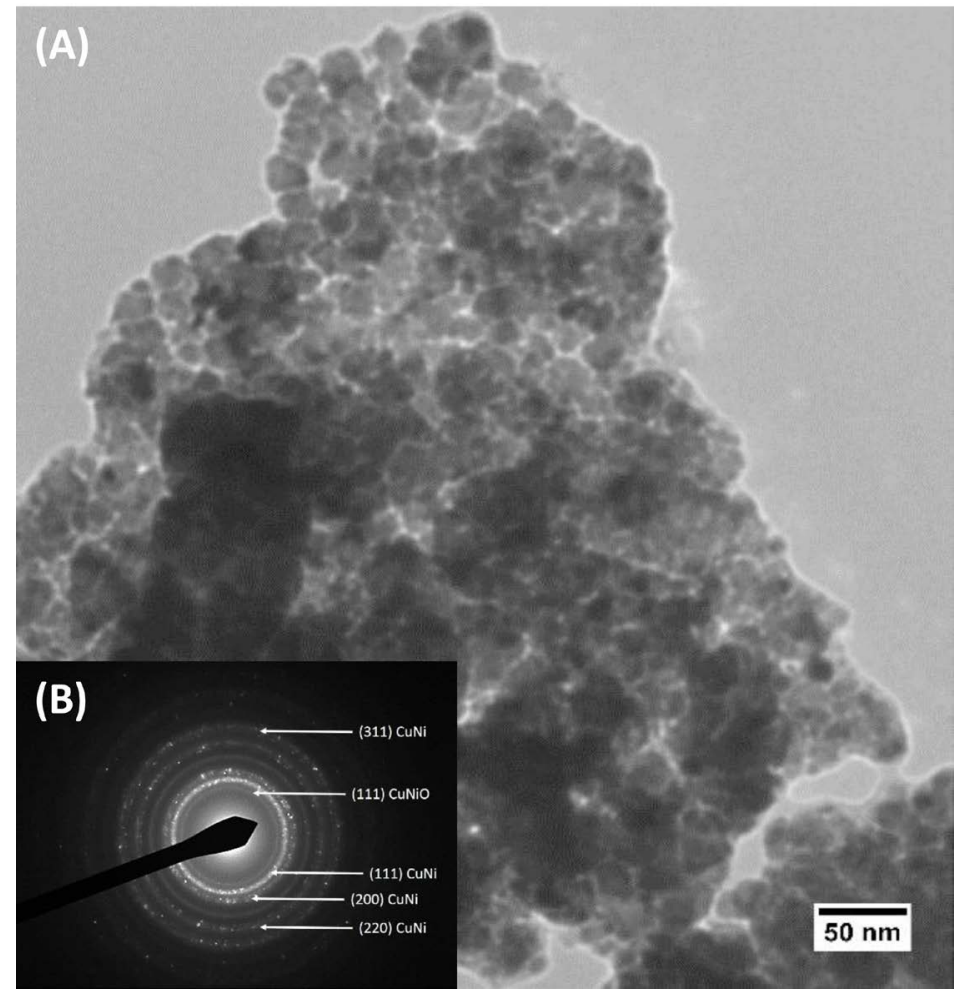

Figure 9. (A) TEM micrograph and (B) electron diffraction pattern of the alloy film.

To study the effect of oxygen exposure on resistance, the sample was printed with copper, nickel and alloy MOD ink on a glass substrate using an inkjet printing technique. The resistance was measured across the sintered sample after every ten passes of the oxygen plasma. Figure 10 shows the change in relative resistance of the printed film with exposure. As expected, the relative resistance of the sintered copper increased due to oxidization as the number of passes were

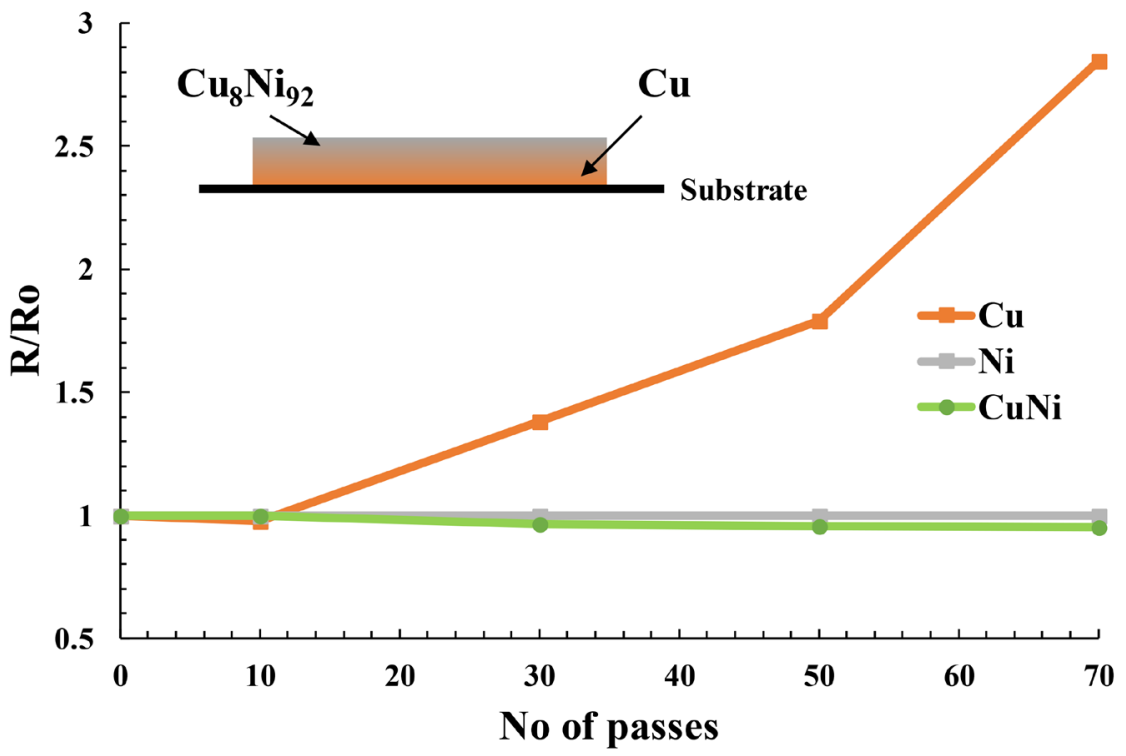

Figure 10. Measured change of resistance in printed film on exposure to oxygen plasma. 
increased. In contrast, the relative resistance of the nickel and copper nickel alloy samples was not affected by the oxidizing environment. This demonstrated ability of the nanoalloy structure to maintain conductivity in a strongly corrosive or oxidative environment suggests numerous potential applications in electronics.

\section{Conclusion}

A new method to easily form copper-nickel nanoalloys directly onto a substrate has been shown. The copper and nickel precursor inks were formulated using metal formate salts, ethylenediamine, and ethylene glycol. The reduction process of copper, nickel and combined solutions was studied in detail. XRD analysis of the sintered alloy shows the presence of two phases, copper and bimetallic copper-nickel. Sintering of the alloy ink resulted in the formation of a copper film on the substrate that was encapsulated by nickel-rich copper-nickel alloy. The lattice constant for the sintered alloy was $3.5318 \AA$, indicating the average composition of the bimetallic alloy to be $\mathrm{Cu}_{8} \mathrm{Ni}_{92}$. The relative resistance change was observed for all MOD inks in an oxidizing environment. After several passes of oxygen plasma treatment, the nanoalloy film demonstrated no change in resistivity values, making the copper-nickel nanoalloy film suitable in oxidizing environments. This research enables the creation of complex shapes and functionally graded materials with a variety of stoichiometric ratios by simply mixing individual metal inks in the desired proportions.

\section{Conflicts of Interest}

The authors declare no conflicts of interest regarding the publication of this paper.

\section{References}

[1] Kahn, B.E. (2015) Patterning Processes for Flexible Electronics. Proceedings of the IEEE, 103, 497-517. https://doi.org/10.1109/JPROC.2015.2401553

[2] Jung, M., Kim, J., Noh, J., Lim, N., Lim, C., Lee, G., Kim, J., Kang, H., Jung, K. and Leonard, A.D. (2010) All-Printed and Roll-to-Roll-Printable 13.56-MHz-Operated 1-Bit RF Tag on Plastic Foils. IEEE Transactions on Electron Devices, 57, 571-580. https://doi.org/10.1109/TED.2009.2039541

[3] Sangoi, R., Smith, C.G., Seymour, M.D., Venkataraman, J.N., Clark, D.M., Kleper, M.L. and Kahn, B.E. (2005) Printing Radio Frequency Identification (RFID) Tag Antennas Using Inks Containing Silver Dispersions. Journal of Dispersion Science and Technology, 25, 513-521. https://doi.org/10.1081/DIS-200025721

[4] Montoya, T.P. and Kirshchenmann, K.J. (2007) Antennas with Discrete Resistive Loading Built by Direct-Write Fabrication. 2007 IEEE Antennas and Propagation Society International Symposium, Honolulu, HI, 9-15 June 2007, 4080-4083. https://doi.org/10.1109/APS.2007.4396437

[5] Yang, L., Rida, A., Vyas, R. and Tentzeris, M.M. (2007) RFID Tag and RF Structures on a Paper Substrate Using Inkjet-Printing Technology. IEEE Transactions on Microwave Theory and Techniques, 55, 2894-2901. 
https://doi.org/10.1109/TMTT.2007.909886

[6] Vaillancourt, J., Zhang, H., Vasinajindakaw, P., Xia, H., Lu, X., Han, X., Janzen, D.C., Shih, W.-S., Jones, C.S. and Stroder, M. (2008) All Ink-Jet-Printed Carbon Nanotube Thin-Film Transistor on a Polyimide Substrate with an Ultrahigh Operating Frequency of Over 5 GHz. Applied Physics Letters, 93, Article ID: 243301. https://doi.org/10.1063/1.3043682

[7] Noguchi, Y., Sekitani, T. and Someya, T. (2007) Printed Shadow Masks for Organic Transistors. Applied Physics Letters, 91, Article ID: 133502. https://doi.org/10.1063/1.2790495

[8] Jabbour, G.E., Radspinner, R. and Peyghambarian, N. (2001) Screen Printing for the Fabrication of Organic Light-Emitting Devices. IEEE Journal of Selected Topics in Quantum Electronics, 7, 769-773. https://doi.org/10.1109/2944.979337

[9] Jo, J., Yu, J.-S., Lee, T.-M. and Kim, D.-S. (2009) Fabrication of Printed Organic Thin-Film Transistors Using Roll Printing. Japanese Journal of Applied Physics, 48, Article ID: 04C181. https://doi.org/10.1143/JJAP.48.04C181

[10] Kopola, P., Tuomikoski, M., Suhonen, R. and Maaninen, A. (2009) Gravure Printed Organic Light Emitting Diodes for Lighting Applications. Thin Solid Films, 517, 5757-5762. https://doi.org/10.1016/j.tsf.2009.03.209

[11] Liu, R., Ding, H., Lin, J., Shen, F., Cui, Z. and Zhang, T. (2012) Fabrication of Platinum-Decorated Single-Walled Carbon Nanotube Based Hydrogen Sensors by Aerosol Jet Printing. Nanotechnology, 23, Article ID: 505301. https://doi.org/10.1088/0957-4484/23/50/505301

[12] Wei, L.-J. and Oxley, C.H. (2016) Carbon Based Resistive Strain Gauge Sensor Fabricated on Titanium Using Micro-Dispensing Direct Write Technology. Sensors and Actuators A: Physical, 247, 389-392. https://doi.org/10.1016/j.sna.2016.06.025

[13] Khan, S., Lorenzelli, L. and Dahiya, R. (2014) Screen Printed Flexible Pressure Sensors Skin. 25th Annual SEMI Advanced Semiconductor Manufacturing Conference (ASMC 2014), Saratoga Springs, NY, 19-21 May 2014, 219-224. https://doi.org/10.1109/ASMC.2014.6847002

[14] Shi, C., Shan, X., Tarapata, G., Jachowicz, R., Weremczuk, J. and Hui, H. (2011) Fabrication of Wireless Sensors on Flexible Film Using Screen Printing and via Filling. Microsystem Technologies, 17, 661-667. https://doi.org/10.1007/s00542-010-1161-2

[15] Deng, D., Jin, Y., Cheng, Y., Qi, T. and Xiao, F. (2013) Copper Nanoparticles: Aqueous Phase Synthesis and Conductive Films Fabrication at Low Sintering Temperature. ACS Applied Materials \& Interfaces, 5, 3839-3846. https://doi.org/10.1021/am400480k

[16] Joo, S.-J., Park, S.-H., Moon, C.-J. and Kim, H.-S. (2015) A Highly Reliable Copper Nanowire/Nanoparticle Ink Pattern with High Conductivity on Flexible Substrate Prepared via a Flash Light-Sintering Technique. ACS Applied Materials \& Interfaces, 7, 5674-5684. https://doi.org/10.1021/am506765p

[17] Joo, S.-J., Hwang, H.-J. and Kim, H.-S. (2014) Highly Conductive Copper Nano/Microparticles Ink via Flash Light Sintering for Printed Electronics. Nanotechnology, 25, Article ID: 265601. https://doi.org/10.1088/0957-4484/25/26/265601

[18] Öhlund, T., Schuppert, A.K., Hummelgård, M., Bäckström, J., Nilsson, H.-E. and Olin, H. (2015) Inkjet Fabrication of Copper Patterns for Flexible Electronics: Using Paper with Active Precoatings. ACS Applied Materials \& Interfaces, 7, 18273-18282. https://doi.org/10.1021/acsami.5b03061

[19] Kim, H.-S., Dhage, S.R., Shim, D.-E. and Hahn, H.T. (2009) Intense Pulsed Light Sintering of Copper Nanoink for Printed Electronics. Applied Physics A: Materials 
Science \& Processing, 97, 791-798. https://doi.org/10.1007/s00339-009-5360-6

[20] Lee, Y., Choi, J.-R., Lee, K.-J., Stott, N.E. and Kim, D. (2008) Large-Scale Synthesis of Copper Nanoparticles by Chemically Controlled Reduction for Applications of Inkjet-Printed Electronics. Nanotechnology, 19, Article ID: 415604. https://doi.org/10.1088/0957-4484/19/41/415604

[21] Li, Y., Wu, Y. and Ong, B.S. (2005) Facile Synthesis of Silver Nanoparticles Useful for Fabrication of High-Conductivity Elements for Printed Electronics. Journal of the American Chemical Society, 127, 3266-3267. https://doi.org/10.1021/ja043425k

[22] Lee, H.-H., Chou, K.-S. and Huang, K.-C. (2005) Inkjet Printing of Nanosized Silver Colloids. Nanotechnology, 16, 2436. https://doi.org/10.1088/0957-4484/16/10/074

[23] Zhang, Z., Zhang, X., Xin, Z., Deng, M., Wen, Y. and Song, Y. (2011) Synthesis of Monodisperse Silver Nanoparticles for Ink-Jet Printed Flexible Electronics. Nanotechnology, 22, Article ID: 425601. https://doi.org/10.1088/0957-4484/22/42/425601

[24] Chen, C.-N., Chen, C.-P., Dong, T.-Y., Chang, T.-C., Chen, M.-C., Chen, H.-T. and Chen, I. (2012) Using Nanoparticles as Direct-Injection Printing Ink to Fabricate Conductive Silver Features on a Transparent Flexible PET Substrate at Room Temperature. Acta Materialia, 60, 5914-5924.

https://doi.org/10.1016/j.actamat.2012.07.034

[25] Zope, K.R., Cormier, D. and Williams, S. (2018) Reactive Silver Oxalate Ink Composition with Enhanced Curing Conditions for Flexible Substrates. ACS Applied Materials \& Interfaces, 10, 3830-3834. https://doi.org/10.1021/acsami.7b19161

[26] Jeong, S., Song, H.C., Lee, W.W., Choi, Y., Lee, S.S. and Ryu, B.-H. (2010) Combined Role of Well-Dispersed Aqueous Ag Ink and the Molecular Adhesive Layer in Inkjet Printing the Narrow and Highly Conductive Ag Features on a Glass Substrate. The Journal of Physical Chemistry C, 114, 22277-22283. https://doi.org/10.1021/jp106994t

[27] Calvo, F. (2013) Nanoalloys: From Fundamentals to Emergent Applications. Elsevier, Massachusetts.

[28] Peng, Z. and Yang, H. (2008) Ag-Pt Alloy Nanoparticles with the Compositions in the Miscibility Gap. Journal of Solid State Chemistry, 181, 1546-1551.

https://doi.org/10.1016/j.jssc.2008.03.013

[29] Andrews, M.P. and O’Brien, S.C. (1992) Gas-Phase "Molecular Alloys" of bulk Immiscible Elements: Iron-Silver (FexAgy). The Journal of Physical Chemistry, 96, 8233-8241. https://doi.org/10.1021/j100200a007

[30] Chatterjee, J., Bettge, M., Haik, Y. and Chen, C.J. (2005) Synthesis and Characterization of Polymer Encapsulated Cu-Ni Magnetic Nanoparticles for Hyperthermia Applications. Journal of Magnetism and Magnetic Materials, 293, 303-309. https://doi.org/10.1016/j.jmmm.2005.02.024

[31] Kline, T.L., Xu, Y.-H., Jing, Y. and Wang, J.-P. (2009) Biocompatible High-Moment FeCo-Au Magnetic Nanoparticles for Magnetic Hyperthermia Treatment Optimization. Journal of Magnetism and Magnetic Materials, 321, 1525-1528. https://doi.org/10.1016/j.jmmm.2009.02.079

[32] W, Q.-W., Y, J.-L., R, J.-F., H, M.M. and Y, C.-H. (1990) Structure and Catalytic Properties of $\mathrm{Cu}-\mathrm{Ni}$ Bimetallic Catalysts for Hydrogenation. Catalysis Letters, 4, 63-74. https://doi.org/10.1007/BF00764872

[33] He, J., Ichinose, I., Kunitake, T., Nakao, A., Shiraishi, Y. and Toshima, N. (2003) Facile Fabrication of Ag-Pd Bimetallic Nanoparticles in Ultrathin $\mathrm{TiO}_{2}$-Gel Films: Nanoparticle Morphology and Catalytic Activity. Journal of the American Chemical 
Society, 125, 11034-11040. https://doi.org/10.1021/ja035970b

[34] Alloyeau, D., Mottet, C. and Ricolleau, C. (2012) Nanoalloys: Synthesis, Structure and Properties. Springer Science \& Business Media, Berlin/Heidelberg, Germany. https://doi.org/10.1007/978-1-4471-4014-6

[35] Ferrer, D., Torres-Castro, A., Gao, X., Sepulveda-Guzman, S., Ortiz-Mendez, U. and Jose-Yacaman, M. (2007) Three-Layer Core/Shell Structure in Au-Pd Bimetallic Nanoparticles. Nano Letters, 7, 1701-1705. https://doi.org/10.1021/nl070694a

[36] Yamauchi, T., Tsukahara, Y., Sakata, T., Mori, H., Yanagida, T., Kawai, T. and Wada, Y. (2010) Magnetic Cu-Ni (Core-Shell) Nanoparticles in a One-Pot Reaction under Microwave Irradiation. Nanoscale, 2, 515-523. https://doi.org/10.1039/b9nr00302a

[37] Choi, E., Lee, S. and Piao, Y. (2015) Asolventless Mix-Bake-Wash Approach to the Facile Controlled Synthesis of Core-Shell and Alloy Ag-Cu Bimetallic Nanoparticles. CrystEngComm, 17, 5940-5946. https://doi.org/10.1039/C5CE00670H

[38] Badawy, W.A., Ismail, K.M. and Fathi, A.M. (2005) Effect of Ni Content on the Corrosion Behavior of $\mathrm{Cu}-\mathrm{Ni}$ Alloys in Neutral Chloride Solutions. Electrochimica Acta, 50, 3603-3608. https://doi.org/10.1016/j.electacta.2004.12.030

[39] Kim, H., Lu, C., Worrell, W., Vohs, J. and Gorte, R. (2002) Cu-Ni Cermet Anodes for Direct Oxidation of Methane in Solid-Oxide Fuel Cells. Journal of the Electrochemical Society, 149, A247-A250. https://doi.org/10.1149/1.1445170

[40] Qiu, R., Zhang, X.L., Qiao, R., Li, Y., Kim, Y.I. and Kang, Y.S. (2007) CuNi Dendritic Material: Synthesis, Mechanism Discussion, and Application as Glucose Sensor. Chemistry of Materials, 19, 4174-4180. https://doi.org/10.1021/cm070638a

[41] Hashemizadeh, S.A. and Biglari, M. (2018) Cu: Ni Bimetallic Nanoparticles: Facile Synthesis, Characterization and Its Application in Photodegradation of Organic dyes. Journal of Materials Science: Materials in Electronics, 29, 13025-13031. https://doi.org/10.1007/s10854-018-9424-2

[42] Kuznetsov, A.A., Leontiev, V.G., Brukvin, V.A., Vorozhtsov, G.N., Kogan, B.Y., Shlyakhtin, O.A., Yunin, A.M., Tsybin, O.I. and Kuznetsov, O.A. (2007) Local Radiofrequency-Induced Hyperthermia Using CuNi Nanoparticles with Therapeutically Suitable Curie Temperature. Journal of Magnetism and Magnetic Materials, 311, 197-203. https://doi.org/10.1016/j.jmmm.2006.11.199

[43] Songping, W., Li, J., Jing, N., Zhenou, Z. and Song, L. (2007) Preparation of Ultra Fine Copper-Nickel Bimetallic Powders for Conductive Thick Film. Intermetallics, 15, 1316-1321. https://doi.org/10.1016/j.intermet.2007.04.001

[44] Ahmed, J., Ramanujachary, K.V., Lofland, S.E., Furiato, A., Gupta, G., Shivaprasad, S. and Ganguli, A.K. (2008) Bimetallic Cu-Ni Nanoparticles of Varying Composition $\left(\mathrm{CuNi}_{3}, \mathrm{CuNi}, \mathrm{Cu}_{3} \mathrm{Ni}\right)$. Colloids and Surfaces A: Physicochemical and Engineering Aspects, 331, 206-212. https://doi.org/10.1016/j.colsurfa.2008.08.007

[45] Feng, J. and Zhang, C.-P. (2006) Preparation of Cu-Ni Alloy Nanocrystallites in Water-in-Oil Microemulsions. Journal of Colloid and Interface Science, 293, 414-420. https://doi.org/10.1016/j.jcis.2005.06.071

[46] Souilah, S., Alleg, S., Bououdina, M., Sunol, J. and Hlil, E. (2017) Magnetic and Structural Properties of the Nanostructured $\mathrm{Cu}_{50} \mathrm{Ni}_{50}$ Powders. Journal of Superconductivity and Novel Magnetism, 30, 1927-1935. https://doi.org/10.1007/s10948-017-4001-0

[47] Bonet, F., Grugeon, S., Dupont, L., Urbina, R.H., Guery, C. and Tarascon, J. (2003) Synthesis and Characterization of Bimetallic Ni-Cu Particles. Journal of Solid State 
Chemistry, 172, 111-115. https://doi.org/10.1016/S0022-4596(02)00163-9

[48] Chen, L., Xu, H., Cui, H., Zhou, H., Wan, H. and Chen, J. (2017) Preparation of $\mathrm{Cu}-\mathrm{Ni}$ Bimetallic Nanoparticles Surface-Capped with Dodecanethiol and Their Tribological Properties as Lubricant Additive. Particuology, 34, 89-96. https://doi.org/10.1016/j.partic.2016.12.006

[49] Jung, C.-H., Lee, H.-G., Kim, C.-J. and Bhaduri, S. (2003) Synthesis of Cu-Ni Alloy Powder Directly from Metal Salts Solution. Journal of Nanoparticle Research, 5, 383-388. https://doi.org/10.1023/A:1025510910814

[50] Pál, E., Kun, R., Schulze, C., Zöllmer, V., Lehmhus, D., Bäumer, M. and Busse, M. (2012) Composition-Dependent Sintering Behaviour of Chemically Synthesised CuNi Nanoparticles and Their Application in Aerosol Printing for Preparation of Conductive Microstructures. Colloid and Polymer Science, 290, 941-952.

https://doi.org/10.1007/s00396-012-2612-3

[51] Pál, E., Zöllmer, V., Lehmhus, D. and Busse, M. (2011) Synthesis of $\mathrm{Cu}_{0.55} \mathrm{Ni}_{0.44} \mathrm{Mn}_{0.01}$ Alloy Nanoparticles by Solution Combustion Method and Their Application in Aerosol Printing. Colloids and Surfaces A: Physicochemical and Engineering Aspects, 384, 661-667. https://doi.org/10.1016/j.colsurfa.2011.05.038

[52] Ginley, D.S., Curtis, C.J., Miedaner, A., Van Hest, M.F.A.M. and Kaydanova, T. (2014) Metal Inks. US Patent No. 8641931 B2.

[53] Farraj, Y., Grouchko, M. and Magdassi, S. (2015) Self-Reduction of a Copper Complex MOD Ink for Inkjet Printing Conductive Patterns on Plastics. Chemical Communications, 51, 1587-1590. https://doi.org/10.1039/C4CC08749F

[54] Shevchenko, E.V., Talapin, D.V., Schnablegger, H., Kornowski, A., Festin, Ö., Svedlindh, P., Haase, M. and Weller, H. (2003) Study of Nucleation and Growth in the Organometallic Synthesis of Magnetic Alloy Nanocrystals: The Role of Nucleation Rate in Size Control of $\mathrm{CoPt}_{3}$ Nanocrystals. Journal of the American Chemical Society, 125, 9090-9101. https://doi.org/10.1021/ja0299371

[55] Gupta, S. (1998) Peak Decomposition Using Pearson Type VII Function. Journal of Applied Crystallography, 31, 474-476. https://doi.org/10.1107/S0021889897011047

[56] Cullity, B.D. (1978) Elements of X-Ray Diffraction. Addison-Wesley Publishing Company, Inc., Massachusetts. 